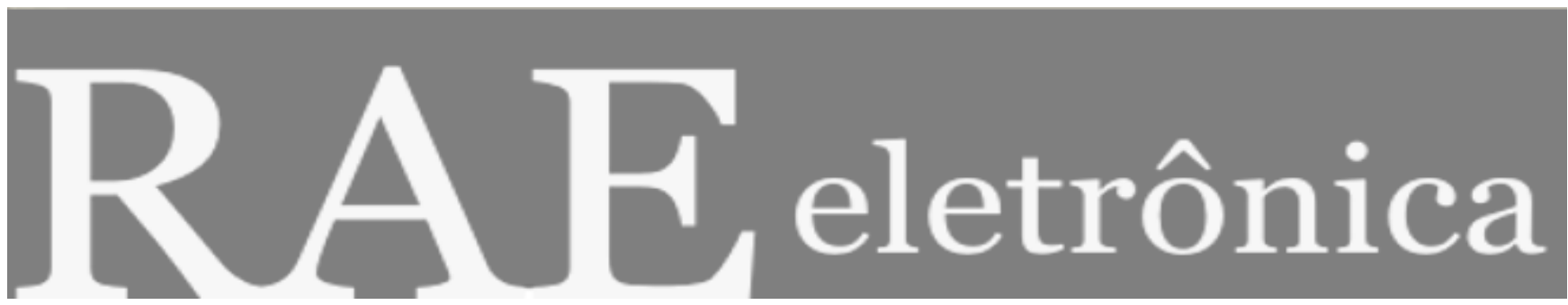

\title{
A APROPRIAÇÃO E RECONTEXTUALIZAÇÃO DE PRÁTICAS ORGANIZACIONAIS
}

Por

Julio Cesar Donadone

RAE-eletrônica, Volume 1, Número 1, jan-jun/2002.

http://www.rae.com.br/eletronica/index.cfm?FuseAction=Artigo\&ID=1281\&Secao=ORGANIZA\&Volume=1\&Numero=1 $\underline{\& A n o}=2002$

CCopyright, 2002, RAE-eletrônica. Todos os direitos, inclusive de tradução, são reservados. É permitido citar parte de artigos sem autorização prévia desde que seja identificada a fonte. A reprodução total de artigos é proibida. Os artigos só devem ser usados para uso pessoal e nãocomercial. Em caso de dúvidas, consulte a redação: redacao@rae.com.br.

A RAE-eletrônica é a revista on-line da FGV-EAESP, totalmente aberta e criada com o objetivo de agilizar a veiculação de trabalhos inéditos. Lançada em janeiro de 2002, com perfil acadêmico, é dedicada a professores, pesquisadores e estudantes. Para mais informações consulte o site www.rae.com.br/eletronica.

RAE-eletrônica

ISSN 1676-5648

(C)2002 Editora: Fundação Getulio Vargas - Escola de Administração

de Empresas de São Paulo.

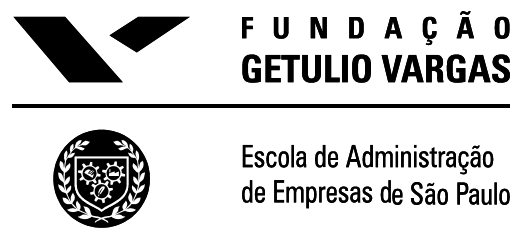




\title{
A APROPRIAÇÃO E RECONTEXTUALIZAÇÃO DE PRÁTICAS ORGANIZACIONAIS
}

\section{Julio Cesar Donadone}

Professor da Universidade Federal de São Carlos.

E-mail:donado@power.ufscar.br

\section{RESUMO}

Neste artigo pretende-se abordar os processos de apropriação e recontextualização de práticas organizacionais a partir da analise da difusão de tecnologias organizacionais associadas à "participação dos trabalhadores nas empresas" no decorrer da década de 1980. O eixo central do trabalho é mostrar como o conceito de "participação" tem seu significado alterado no decorrer do período para se adaptar às mudanças nos contextos sociais, econômicos e culturais. Contrariando o entendimento mais comum, sustento que longe de ser um problema de falta de precisão do conceito de participação, esta plasticidade é justamente a condição para sua difusão e introdução de maneira concreta no ambiente organizacional brasileiro.

\begin{abstract}
In this article it intends to approach the appropriation/reconstruction processes of practices organizational starting from it analyses of the diffusion of technologies organizational associated to the workers' participation in the companies " in elapsing of the decade of 1980. The central axis of the work is to show as the participation " concept has your meaning altered in elapsing of the period to adapt to the changes in the contexts. Thwarting the most common understanding, I sustain that far away from being a problem of lack of precision of the participation concept, this plasticity is exactly the condition for your diffusion and introduction in a concrete way in the atmosphere Brazilian organizational
\end{abstract}

PALAVRAS-CHAVE

Difusão, participação, polissemia, mudança organizacional.

\section{KEY WORDS}

Diffusion, participation, polyssemy, organizational change. 


\section{INTRODUÇÃO}

O início da década de 1980 foi marcado pelo incremento no ritmo de introdução de mudanças tecnológicas e organizacionais nas empresas brasileiras. Tais mudanças foram motivadas pela necessidade de fazer com que as empresas reagissem à recessão econômica interna e buscassem mercados exteriores. Conceitos como qualidade e flexibilidade surgiram no elenco de inovações adotadas, visando a reestruturar a produção industrial e assim, melhorar os índices de competitividade.

Dentre as mudanças de natureza organizacional que se propunha, evidenciava-se, de maneira mais freqüente, a procura por uma nova relação entre as empresas e seus funcionários, o que proporcionou o desenvolvimento de formas inéditas de negociação e integração entre empregado e empregador. Entre essas formas surgem os chamados "sistemas participativos", que se difundiram nas organizações brasileiras nos anos que se seguiram, resultando em uma diversidade de arranjos organizacionais e entendimentos associados ao tema "participação".

Considerando o contexto político, social e econômico em que esse processo de mudanças organizacionais se impôs às empresas brasileiras, pretende-se, neste artigo, abordar a difusão de tecnologias organizacionais associadas à "participação dos trabalhadores nas empresas" no decorrer da década de 1980. O eixo central do trabalho é mostrar como o conceito de "participação" tem seu significado alterado no decorrer do período para se adaptar às mudanças nos contextos. Contrariando o entendimento mais comum, sustento que longe de ser um problema de falta de precisão do conceito de participação, esta plasticidade é justamente a condição para sua difusão e introdução de maneira concreta no ambiente organizacional brasileiro.

Para que se alcance tal intuito, o presente trabalho utiliza como material primário de análise o rastreamento sistemático das apreciações sobre o tema veiculadas na imprensa de negócios brasileira, em especial a revista Exame, no período de 1967 a 1990, visando observar as mudanças de sentido que o termo vai adquirindo no decorrer do tempo. Como contraponto à imprensa de negócios com seu caráter de porta-voz do pensamento gerencial e empresarial, serão utilizados os dados que constam nos arquivos de publicações sindicais das décadas de 1970 e 1980 do Departamento Intersindical de Estudos Estatísticos e Socioeconômicos (DIEESE), buscando, assim, sistematizar a visão sindical sobre o tema.

O material de análise é complementado por informações extraídas de entrevistas com participantes do processo de difusão, como, por exemplo, jornalistas, membros de associações profissionais, empresas de consultoria e pela consulta de literatura sobre o assunto.

\section{A difusão de idéias VERSUS A difuSÃo de PRÁtiCAS}

Para que se compreenda como as idéias sobre "participação" foram incorporadas e transformadas em "prática" nas organizações brasileiras, considerou-se a análise dos diversos significados atribuídos ao tema no transcorrer da década de 1980.

O conceito de participação foi se modificando em virtude da existência de uma disputa entre os diversos setores empresarial, sindical e gerencial pela definição válida na sociedade sobre o conteúdo das novidades organizacionais associadas a ela. Para que se entenda essa plasticidade, utiliza-se como conceito central a idéia de "polissemia". Segundo Bourdieu (1989), entende-se por polissemia um 
sentido parcialmente compartilhado para um determinado conceito, onde os entendimentos implícitos na sociedade em torno de sua definição fixam-se neste compartilhamento apenas parcial, que garante um mínimo de acordo e evita uma crise na relação entre os contendores, para depois evoluir como conflitos simbólicos, em que cada parte tenta registrar como correta a sua versão específica do entendimento. Em outras palavras, o entendimento parcial em torno do tema "participação" possibilitou a negociação entre os empregados e as empresas durante os movimentos grevistas de 1978, garantindo benefícios mútuos, com o reconhecimento do sindicato como interlocutor dos trabalhadores pelas empresas e a utilização desse canal de comunicação como forma de resolver os conflitos trabalhistas.

Assim, no começo da década de 1980, forma-se um "campo", conforme a conceituação de Bourdieu, em torno do tema, onde os diversos agentes envolvidos colaboravam para sua difusão e consolidação nas organizações brasileiras. Para tanto, eles utilizaram-se da possibilidade de um mínimo de entendimento comum sobre o tema "participação", como uma forma de alcançar os seus objetivos específicos sobre um futuro desejado nas relações trabalhistas.

Depois de algum tempo, esse acordo explícito inicial evoluiu para uma luta simbólica, em que os diversos grupos de atores sociais buscaram legitimar sua versão de "participação", desqualificando as demais formas. Cada grupo de atores envolvido com o tema buscava uma compreensão própria sobre as práticas participativas veiculadas às idéias de gestão japonesas e de mudanças organizacionais, com certa influência da proposta sócio-técnica, utilizando-a na tentativa de alavancar e fortalecer sua posição frente aos concorrentes do campo.

A luta pela definição social do significado da "participação", além de fornecer os diversos entendimentos sobre o tema, surgiu como um dos pontos principais do processo de difusão das tecnologias organizacionais associadas às idéias de gestão oriunda da chamada administração industrial japonesa e também da "reengenharia" no decorrer da década de oitenta. Pois, como afirma Cole, para que o processo de difusão de novas tecnologias tenha sucesso é necessário "reinventar a roda". Assim, as novidades organizacionais associadas à "participação" difundiram-se no transcorrer dos anos oitenta, porém somente entraram realmente no cotidiano das empresas, após um processo de apropriação/recontextualização, quando seu "espírito" foi progressivamente assimilado a práticas já conhecidas no nosso ambiente, fornecendo-lhes um sentido compreensível no sistema social das organizações brasileiras. Como exemplo, pode-se citar a utilização de metáforas nos meios gerenciais brasileiros no final dos anos oitenta, associando o tema "participação" a aspectos relativos ao futebol. Um dos mais freqüentes era a idéia: "quem ganha o jogo é o time". Com isso, ressaltava-se que, assim como no futebol, também nas empresas, o sucesso dependia do grupo, pois, segundo a crônica futebolística, não havia mais espaço para um "craque" que sozinho resolveria o jogo, atuando somente no ataque, mas sim a necessidade de, ao mesmo tempo, "fazer gols" e "ajudar na defesa".

\section{A "PARTICIPAÇÃo dos TRABALHAdORES" ANTES DA DÉCADA DE OITENTA: "O EsTRANHO NO NINHO"}

Com o objetivo de fornecer um panorama do tema "participação" antes da década de oitenta, servindo de subsídio para o entendimento que o tema tomaria nos anos seguintes, enfocamos, primeiramente, o período de 1967 a 1977. A escolha do ano de 1967, como ponto de partida para esta pesquisa, deve-se, por um lado, ao fato de ter sido neste ano o lançamento do encarte "Negócios em Exame" nas revistas técnicas da Editora Abril, que posteriormente, em 1971, se tornaria a Revista Exame, uma das fontes primárias deste trabalho; por outro lado, à possibilidade de se inserirem, na análise, as greves de 
Contagem e Osasco ocorridas em 1968, que forneceram importantes elementos para a caracterização da visão sindical sobre o tema "participação" no período anterior aos anos oitenta.

Ao analisar o período de 1967 a 1977, a primeira constatação é a de que o tema participação era pouco evidenciado. Diversos fatores contribuíram para que o tema não fosse divulgado. Na esfera política, o autoritarismo e as formas de repressão utilizadas pelo regime militar inibiam ou tornavam desnecessárias a constatação de problemas de relações trabalhistas. $\mathrm{Na}$ imprensa de negócios, o tema "participação" era pouco citado e os esporádicos exemplos resumiam-se a notícias sobre empresas que adotavam "estranhas formas de gestão", apresentando o assunto para os leitores/gerentes mais como uma curiosidade do que como algo viável no gerenciamento das empresas. Do lado sindical, o quadro não era diferente. Ao pesquisar os artigos publicados nos boletins do DIEESE, durante o período de 1967 a 1978, não foi encontrada qualquer referência ao tema, e mesmo nas greves de $1968 \mathrm{em}$ Contagem e Osasco, a participação via "comissões de fábrica" aparecia como uma ameaça às posições dos sindicatos, no entender da maioria dos dirigentes sindicais da época. Como exemplo, é possível considerar o fato de que a Volkswagem, em 1971, a Johnson \& Johnson, em 1972, e a Empresa Brasileira de Aeronáutica (EMBRAER), em 1974, introduziram Círculos de Controle de Qualidade (CCQs) e não foram notícia na Revista Exame, nem tampouco nas publicações sindicais do período de 1967 a 1978. Tais posturas diferiam das adotadas na década de oitenta, quando a participação, associada aos CCQs, recebia expressiva divulgação na imprensa de negócios e tinha críticas constantes nos jornais e boletins sindicais.

\section{A DIFUSÃO DE IDÉIAS ASSOCIADAS À “PARTICIPAÇÃO DOS TRABALHADORES” NA DÉCADA DE 1980}

A difusão de idéias sobre "participação" entre os trabalhadores foi influenciada por acontecimentos políticos e sociais no decorrer da década de 1980. O fim do regime militar, as greves de 1978, a recessão dos anos 1980-83 e a atuação dos diversos setores sociais envolvidos, induziram a um número crescente de experiências associados ao tema.

Diferentemente do período de 1967 a 1978, as idéias de "participação" começavam a ganhar evidência no final dos anos setenta. Tal fato deve-se, principalmente, ao ressurgimento dos movimentos trabalhistas e sindicais, após as greves de 1978. Com a perda do espaço antigamente ocupado pelo governo, como mediador entre empresários e trabalhadores, coube a estes vivenciarem a experiência da negociação direta, na tentativa de resolverem os embates trabalhistas. Esse fato impulsionou a discussão das formas de intervenção dos operários em aspectos da vida das empresas, proporcionando os primeiros significados associados à participação da década de 1980. Os primeiros exemplos de introdução de "Representantes dos Trabalhadores" e "Delegados Sindicais", a criação de "comissões de fábrica" e a discussão sobre a intervenção dos trabalhadores em assuntos referentes ao mundo fabril colocavam em evidência o tema "participação dos trabalhadores nas empresas".

$\mathrm{O}$ assunto era destaque nas publicações sindicais, aparecendo como um dos fatores que diferenciavam o sindicalismo que surgiu após as greves 1978 das formas anteriores, então chamadas de "pelegas". Assim sendo, a "participação" estava associada a formas de negociação direta com o patronato e à possibilidade de ampliação do elenco das pautas de reivindicação, passando a abranger não somente aspectos salariais, mas também, questões relacionadas ao cotidiano do chão de fábrica.

$\mathrm{Na}$ estratégia geral do movimento sindical da época, a participação surgia como uma alternativa de atuação face à ação repressora do regime militar. Negociando com as empresas uma introdução de representantes dos trabalhadores, os dirigentes sindicais vislumbravam uma forma de garantir a atuação 
do movimento sindical frente à sempre presente possibilidade de cassação de líderes e à intervenção nos sindicatos pelo governo militar.

Mas não era apenas nos meios sindicais que o tema "participação" recebia destaque. Ele começava a ser pauta também, nas publicações empresariais e gerenciais. As notícias apresentavam exemplos de empresas que estabeleciam "novas formas" de negociação com os empregados, na tentativa de solucionar os embates trabalhistas por elas enfrentados com o recrudescimento do movimento sindical no "pós-1978" e a mitigação na atuação do governo como mediador entre empregados e empregadores que era, até então, exercida amplamente pelo regime militar. Surgiam os primeiros exemplos de empresários e gerentes discutindo a respeito da "participação", mais especificamente sobre a criação de representantes dos trabalhadores nas empresas, na tentativa de evitar que problemas passíveis de serem resolvidos no interior da empresa fossem direcionados para possíveis movimentos grevistas.

O início da divulgação e da discussão de significados atribuídos ao tema "participação", representados pelo "Delegado Sindical", "Representantes de Empresas" e pelas "Comissões de Fábrica" são de grande valia para a proposta de explicação do caráter polissêmico do conceito. No período de 1978 a 1982 a "participação", considerada como sendo um canal de comunicação, começava a ser divulgada na imprensa de negócios e aceita tanto nas empresas como nos meios sindicais. Cabe lembrar que as comissões de fábrica eram também uma forma de "representantes dos trabalhadores" nas empresas, diferindo quanto ao grau de controle sindical

Assim, no começo da década de 80, ocorria o entendimento parcial em torno do conteúdo associado ao tema "participação" que possibilitava a negociação entre os empregados e as empresas durante os movimentos grevistas de 1978, garantindo benefícios mútuos, com o reconhecimento do sindicato como interlocutor dos trabalhadores pelas empresas, possibilitando a continuidade da sua atuação frente às condições políticas da época; e a utilização pelas empresas desse canal de comunicação como forma de resolver os conflitos trabalhistas. Para as empresas, essa canalização dos conflitos exorcizava os fantasma da eclosão de "greves selvagens", que tanto assustava as empresas européias no final dos anos sessenta e início da década de setenta.

Dessa maneira, começava a formar-se um "campo" ao redor do tema (BOURDIEU,1989). Nele, os diversos agentes envolvidos colaboravam para sua difusão e consolidação nas organizações brasileiras. Para tanto, eles nutriam-se daquele mínimo de entendimento comum sobre o conteúdo do conceito de "participação". Partindo desse núcleo comum, cada grupo tentava forçar o significado do tema, vendo nesse processo uma forma de alcançar os seus objetivos específicos sobre o que eles imaginavam ser o futuro desejado das relações trabalhistas. Estavam lançadas idéias de envolvimento operário com as empresas que posteriormente, no transcorrer da década de oitenta, receberiam novos significados.

\section{Participação e Produtividade : O Período de 1982 a 1987}

Na primeira metade dos anos 1980, outro elemento incrementou a difusão das idéias de participação. A forte recessão interna, nos anos de 1980 a 83, fez com que as empresas buscassem a melhoria dos índices de produtividade, para poderem sobreviver diante de mercados internos em retração e possibilitar a introdução dos produtos brasileiros nos mercados externos, mais competitivos. Esses fatos, entre outros, ocasionaram um aumento no ritmo de introdução das mudanças organizacionais nas empresas brasileiras.

Entre as mudanças, destacava-se a implementação de ferramentas gerenciais inspiradas nas idéias de gestão empresarial japonesa, tal como eram retratadas em publicações da imprensa de negócios norte- 
americana. Tais ferramentas, respaldadas pela divulgação do sucesso das indústrias japonesas, em especial no que diz respeito à conquista de consideráveis parcelas do mercado norte-americano de automóveis, apareciam como uma referência para as empresas brasileiras que buscavam superar os problemas ocasionados pela recessão.

A introdução de formas de gestão japonesa por meio de programas de qualidade causou um significativo incremento na difusão de idéias associadas a "participação". Em especial, pela divulgação e implantação de ferramentas gerenciais que propunham a utilização de intervenções dos trabalhadores nos acontecimentos do chão de fábrica como uma forma de aumento da produtividade e a melhoria da qualidade dos produtos.

Na metade da década de 1980, entre as várias mudanças organizacionais associadas a "idéias japonesas" de gestão da produção, surgiam com destaque: os Círculos de Controle da Qualidade (CCQs). Com os CCQs, o tema "participação" ganhava relevância nas discussões empresariais e gerenciais. Sua divulgação tornava-se freqüente na imprensa de negócios, principalmente, por meio de exemplos de empresas que estavam implementando alguma forma de envolvimento dos operários com a produção.

Como exemplo do crescimento das publicações sobre o tema "participação" que utilizava o modelo japonês como referência, temos o gráfico a seguir.

\section{Os CCQs na Revista Exame}

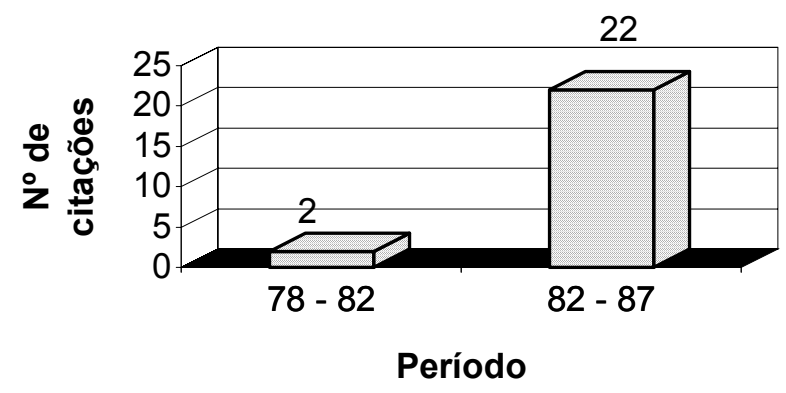

Não era apenas na imprensa de negócios que a "participação" ganhava espaço. Nas publicações sindicais isso também ocorria. No período 1982-87, apareceram diversos artigos que criticavam o envolvimento do operário com a empresa através dos "CCQs". Tais publicações, ainda que de forma inversa à imprensa de negócios, ajudavam na difusão das idéias de "participação", principalmente por meio de discussões e publicações que buscavam contrastar a visão sindical de "participação", preponderantemente associada às Comissões de fábrica, do ponto de vista gerencial representado, principalmente, pelos CCQs.

Naquele momento, os antagonismos escamoteados no acordo inicial em torno de tema "participação" começavam a aparecer em novas contendas. Isto ocorria através do embate entre as Comissões de Fábrica e os Círculos de Controle de Qualidade. As comissões associavam ao tema um conceito que o apresentava como um instrumento de atuação operária no interior das empresas, possibilitando a intervenção sindical em assuntos relacionados à gestão e ao funcionamento das mesmas. Já com os CCQs, o significado atribuído à "participação" passava a associá-la a uma ferramenta gerencial que utilizava os canais de comunicação com a finalidade de redução de custos e integração dos 
funcionários e, em muitos casos, também na tentativa de diminuir a influência dos sindicatos nos ambientes fabris.

Entretanto, cabe ressaltar que a variação dos significados (polissemia) atribuídos a "participação" de acordo com os setores envolvidos consolida o campo em torno do tema. A "participação" foi gradualmente se institucionalizando nos meios empresariais, gerenciais e sindicais brasileiros no decorrer da década de 1980, contando para isso com: i) as empresas, que passaram a visualizá-la como uma das possíveis ferramentas gerenciais de aumento da produtividade; ii) a imprensa de negócios, que encontrava um ótimo filão jornalístico na divulgação "novidades tecnológicas e organizacionais", estruturando um setor especializado. Isso colaborava em muito para a divulgação de exemplos de implementação e discussões a respeito da necessidade dos gerentes implementarem a "participação dos trabalhadores"; iii) o meio sindical, que contribuía por meio de reivindicações e da introdução de formas de intervenção operária, representadas principalmente pelas comissões de fábrica, mas também pelas crescentes publicações que debatiam os CCQs. Além desses fatores, não se pode deixar de mencionar a atuação de firmas de consultoria que implementavam programas de Qualidade, com a presença de CCQs em muito deles.

Assim, o tema "participação", através da variação de significados a ele atribuída, de acordo com os setores envolvidos, foi gradualmente se institucionalizando nos meios empresariais, gerenciais e sindicais brasileiros no decorrer da década de 1980. Dessa maneira, foi-se diferenciando de anos anteriores, quando eram esporádicos os exemplos de empresas que buscavam alguma forma de envolvimento dos funcionários, e o assunto praticamente não figurava nas publicações da imprensa de negócios ou de organizações sindicais.

\section{A Conclusão do Período: A Administração Participativa e Produção do "Guru" GERENCIAL BRASILEIRO}

No final da década de oitenta, novos elementos viriam modificar o conteúdo associado às idéias sobre a participação dos trabalhadores e incrementar seu processo de difusão. Nesse período, começavam a ser divulgadas e implementadas as idéias de reengenharia, enfatizando a necessidade de incremento na flexibilidade de atuação das empresas, na tentativa de acompanharem as oscilações do mercado interno e de aumentarem competitividade nas exportações. As mudanças organizacionais associadas à reengenharia enfocavam a simplificação e a redefinição das estruturas administrativas das empresas, principalmente pela redução de níveis hierárquicos e reformulação dos atributos gerenciais; bem como pela implantação da "participação" dos operários, para agilizar a solução e comunicação de problemas relacionados com a produção.

No período, o tema "participação" ganhou destaque e espaço nas publicações da imprensa brasileira de negócios. Na revista Exame, o assunto que se tornara pauta no transcorrer dos anos oitenta, recebeu uma atenção ainda maior, sendo pela primeira vez, na história da revista, a capa e principal assunto na publicação de março de 1990, com o título: "Quem ganha o jogo é o time". O começo do fim da era one man show, os ideais da chamada "Administração Participativa", na qual a voz do empregado é moeda forte, invadem os escritórios de todo mundo.

O processo de difusão das idéias de "downsizing", reorganização dos processo decisórios e redução dos níveis hierárquicos trouxe modificações no significado atribuído ao tema "participação" dos trabalhadores na imprensa de negócios e nas empresas. No final da década, com a divulgação das idéias de reengenharia, a "participação" passava a ser associada não somente ao incremento da produtividade 
no chão de fábrica, como foram os CCQs, mas também com a redistribuição dos processos de decisão na empresa. Como esperado, o próprio nome já diferia, pois se na metade da década de oitenta, auge da divulgação das idéias sobre a administração industrial japonesa, a participação estava associada ao "Círculo de Controle de Qualidade", designando uma função de acompanhamento do transcorrer do fluxo de produção, com o objetivo de redução de custos, na época da reengenharia, o tema vinha inserido na "Administração Participativa", ou seja, o envolvimento operário visando à flexibilidade das ações e a troca de informações na empresa, e tornando desnecessária a supervisão direta e os diversos níveis de gerenciamento, que passaram a ser vistos como fontes de enrijecimento e de "burocratização" das decisões da empresa.

Apesar dos dados disponíveis sobre a utilização de CCQs nas empresas serem imprecisos, pode-se observar que essa caracterização de "participação" começou a decair na imprensa de negócios e nas empresas a partir de 1987, como se demonstra a seguir.

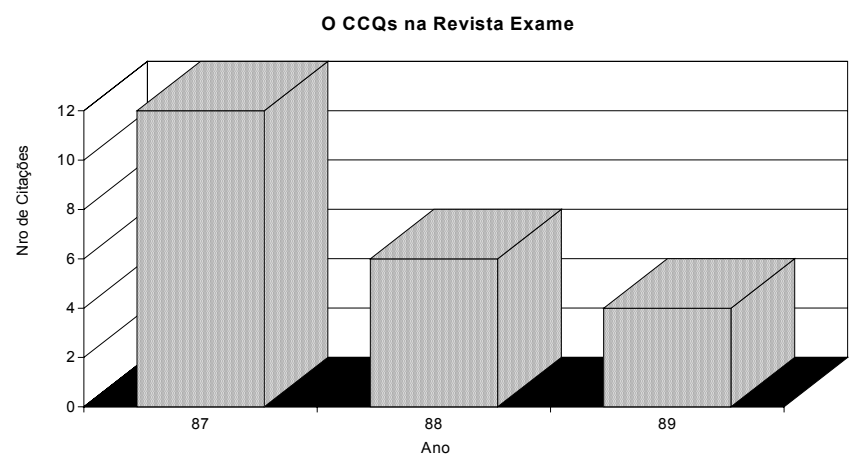

Fonte: Yokoyama,1995

Dados da Fundação Chistiano Ottoni, uma das principais entidades de divulgação das idéias associadas às ferramentas gerenciais da qualidade, confirmavam a tendência apontada anteriormente. Pesquisa realizada em 164 empresas de todo o país, no ano de 1991, indicou que 30\% das empresas que introduziram os Círculos de Controle de Qualidade desistiram da experiência. Segundo o Consultor Claudius D'Artaghan, um dos pioneiros na implantação dos CCQs no Brasil, "os CCQs viraram um nome meio maldito, porque não funcionou em algumas empresas". Sua estimativa era a de que, em 1988, o número de empresas que usavam o CCQ tinha sido reduzido de 2000 para 600. (Revista Exame, Fevereiro de 1988).

Ao se analisar a mensagem passada aos leitores/gerentes pelos exemplos da revista, depara-se com dois componentes básicos: i) quanto à "participação", é possível observar que estava associada a uma forma de agilizar e descentralizar as decisões da empresa, com o objetivo de tornar o grupo de trabalhadores o mais auto-suficiente possível para resolver problemas cotidianos da produção, visando o aumento de flexibilidade, produtividade e tornando desnecessária a supervisão direta; ii) quanto à função gerencial, pode-se dizer que os exemplos reportavam à necessidade de mudanças de atitudes dos gerentes para uma maneira de administrar a empresa que levasse em conta as experiências e a possibilidade de intervenção rápida dos empregados nos acontecimentos diários, dando mais flexibilidade e agilidade nas decisões. Como condição para sobreviver aos cortes nos cargos gerenciais, os gerentes deveriam "delegar e orientar" as tarefas, ao invés de somente fiscalizá-las. Isso ficava claro através das reportagens, nas quais enfatizava-se a redução dos níveis hierárquicos, que 
passaram a ser vistos como fontes de morosidade e fatores que impediam a flexibilidade da empresa. Tal direcionamento era expresso nas palavras do então presidente do grupo Rhodia, empresa referência das mudanças organizacionais do período, Edson Vaz Musa: "eu mesmo tenho grande dificuldade de delegar poderes aos outros mas estou convencido que esse é o caminho"; "ganharemos em dinamismo e a médio prazo, isso fará aumentar a produtividade e a lucratividade da empresa" (Revista Exame, outubro1990).

Assim, na difusão da "participação" pela imprensa de negócios, além do processo mimético ocasionado pela divulgação dos exemplos de empresas que obtinham resultados "positivos" com a introdução da "participação" dos funcionários, há também a presença do isomorfismo normativo. Nas publicações, o gerente "moderno", que tinha maiores possibilidades de sobreviver aos cortes da empresa, deveria facilitar o envolvimento dos trabalhadores nas decisões sobre os problemas cotidianos das empresas. Como exemplo desse "novo gerente", em evidência nas reportagens, temos matéria de junho de 1990, com o título: "Os executivos dos anos noventa". Nela havia uma discussão a respeito das características do gerente dos anos 1990, indicando um fortalecimento dos gerentes "bons negociadores" que proporcionavam um clima de maior envolvimento e participação dos funcionários nas decisões sobre as tarefas a serem executadas.

\section{As Idéias de RiCARdo SEMler E A DIFUSÃo DA "AdMinistraÇÃo PARTICIPATIVA"}

No final dos anos oitenta, as notícias a respeito de mudanças na gestão das empresas traziam freqüentemente referências ao empresário Ricardo Semler. A sua presença era comum nas reportagens da principais revistas, figurava em diversas matérias da Exame, foi personagem das páginas amarelas da Veja, era íntimo dos leitores do jornais Folha de São Paulo, Estado de São Paulo, O Globo, Jornal do Brasil e participava dos mais requisitados programas de televisão. Nenhum outro empresário, mesmo dono de empresas trinta ou quarenta vezes maiores que a Semco, tinha uma exposição positiva na mídia equivalente à de Semler.

Ricardo Semler converteu-se em "celebridade nacional", aos 28 anos, com o lançamento do livro "Virando a Própria Mesa", que estava no final de 1990 em sua vigésima sexta edição, com 180.000 exemplares vendidos, tornando-se um "best seller" nacional. No livro, Semler contava como conseguiu tornar a Semco, que recebeu, em 1982, do pai Antônio Semler, pequena e à beira da insolvência, em uma empresa de médio porte alguns anos depois. Para isso, optou por buscar a saída dos problemas financeiros no envolvimento e participação dos funcionários e nas mudanças da estrutura gerencial da empresa.

O livro de Semler apresentava características que o aproximavam das publicações de "sucesso" na imprensa de negócios da época, como a obra de A. Morita/Made in Japan, sobre a Sony. Através das experiências empresariais e gerenciais desenvolvidas na Semco, Semler procurava indicar uma forma de atuação dos gerentes frente à necessidade de mudanças organizacionais, que se fazia presente em diversas empresas na época, apresentando-a como um "remédio" indicado para empresas que estavam "doentes" na sua estrutura organizacional. Isso ficava claro na abertura do livro, quando era apresentada uma Bula, em que se procurava mostrar o modo de usar, as indicações (para a hipertensão administral e hipertrofia organizacional); e Posologia (para adultos em cargos de direção). Utilizandose das formulações teóricas da obra de Huczynski (1993), na qual o autor discute como se formam e atuam os "gurus gerenciais" na década de 1980, é possível encontrar no livro de Semler características que o aproximam das obras dos "gurus" relacionados com os "gerentes heróis". Por exemplo, o livro de Iacocca. L., An Autobiography, no qual o autor contava os segredos para se obter o "sucesso 
gerencial" por meio da sua experiência de remodelar as empresas automobilísticas Ford e Chrysler, superando seus problemas econômicos. Assim deve-se ter presente o caráter inédito da obra de Semler no panorama editorial brasileiro. Seu livro foi o único do gênero escrito por um brasileiro, que, dessa forma, alcançou o status de "guru gerencial", gozados por Morita A., Iacocca L., entre outros do cenário mundial.

As características da obra de Semler representavam um importante fator para sua divulgação na imprensa de negócios. No transcorrer da década de oitenta, a imprensa brasileira de negócios utilizouse da divulgação das notícias a respeito das mudanças das empresas como um importante elemento para sua consolidação. Dessa maneira, no final dos anos oitenta, o setor de negócios brasileiro vislumbrava, na divulgação de idéias gerenciais aos seus leitores/gerentes, um importante filão de mercado, da mesma forma que a imprensa de negócios norte-americana fizera no início da década de oitenta. Assim sendo, o livro e as idéias de Semler surgiam como uma importante fonte de matérias para uma imprensa ávida de notícias e que, num procedimento considerado inevitável pelos manuais e pela cultura profissional do jornalismo, necessitava "personalizar" (na figura do "empresário-guru") o processo de mudanças, procurando com isso, contextualizar para o mundo gerencial e empresarial brasileiro as alterações organizacionais associadas as novidades empresariais de então.

No final da década de oitenta, a mensagem de Ricardo Semler ecoava nos meios gerenciais brasileiros. Para os gerentes que atuavam nas empresas, as idéias de Semler serviam como guia na tentativa de adaptar-se às mudanças organizacionais que modificavam e desqualificavam as funções da média e baixa gerência. É possível verificar tal fato nas opiniões a seguir: Segundo Celso Calia, diretor de planejamento da empresa de autopeças Garrett, " a experiência da Semco é o grande acontecimento na área de administração e fonte de inspiração para os que têm necessidade de reformar as relações dentro da empresa". Na mesma direção, Felipe Westin, diretor de recursos humanos da subsidiária brasileira da Monsanto, "a Semco é um exemplo extremamente positivo de inovação na área das relações trabalhistas, sendo que seu fenômeno tem que ser estudado com muito carinho" (Revista Exame, suplemento "Maiores e Melhores", Agosto de 1990).

Já para os postulantes aos cargos gerenciais, a interpretação de Ricardo Semler sobre o envolvimento operário fornecia uma poderosa arma na luta por posições nas empresas, que se tornava cada vez mais acirrada com a redução dos níveis hierárquicos associada às idéias de simplificação das estruturas da empresa. Um indicativo de tal fato era a presença constante do nome de Semler na lista de homenageados das escolas de engenharia e administração no período. Ele disputava espaço nas indicações com nomes tradicionais do empresariado brasileiro como Antônio Hermínio de Moraes (grupo Votorantin) e José Mindlin (Grupo Metal Leve), contanto para isso, com justificativas que aliavam uma "nova forma de gerenciar as empresas" à imagem de juventude Semler.

A divulgação alcançada na imprensa levou diversos grupos de empresários e estudantes a visitar a fábrica do bairro de Santo Amaro, em São Paulo. Entre 88-90, mais de mil pessoas estiveram em suas instalações; entre os participantes figuravam o grupo financeiro Chase Manhattan, a construtora Mendes Júnior e a metalúrgica Continental 2001.

Assim, ao vislumbrar-se a divulgação alcançada por Semler, é possível entrever aspectos relevantes da dinâmica do campo formado em torno do tema "participação" no final da década de oitenta. Dentre eles, cabe ressaltar, o processo de "entre legitimação", que ocorre entre a imprensa de negócios e Semler. Para a primeira, que no decorrer da década valeu-se da divulgação de notícias sobre mudanças organizacionais como o principal instrumento de sua consolidação no meio jornalístico, o sucesso das 
propostas de Semler conferia legitimidade e realimentava as possibilidades de atuação. Como contraponto deste processo, a "participação" associada a uma ferramenta gerencial, com o objetivo de tornar o grupo de trabalhadores capaz de resolver problemas cotidianos da produção, visando o aumento de flexibilidade, produtividade e tornando desnecessária a supervisão direta, como postulado por Semler, encontrava na imprensa de negócios uma importante fonte de divulgação. Fato este que veio incrementar o processo de isomorfismo mimético, como também, fortalecer as posições dos agentes do campo que atribuíam um conteúdo gerencial ao tema.

\section{A Visão SindiCAL de "PARTICIPAÇÃo" NO FINAL dOS ANOS OITENTA}

Da mesma forma que na imprensa de negócios e nas empresas, no universo sindical o conceito de "participação" também passava por transformações no final da década de oitenta. Nos artigos do Boletim DIEESE começavam a surgir referências à introdução de "trabalho participativo" nas empresas. Entretanto, não havia uma diferença clara de significados entre o "trabalho participativo" e os CCQs. Os dois mecanismos eram entendidos como formas de apropriação, por parte das gerências, de conhecimentos dos trabalhadores quanto ao funcionamento da fábrica e que se contrapunham à versão sindical de "participação", associada às Comissões de Fábrica.

Mas se comparamos os artigos que tratavam da introdução dos CCQs, do período de 1982 a 1987, com aqueles que faziam referências ao "trabalho participativo" no final da década de oitenta, pode-se ver diferenças significativas. No caso dos CCQs, eles eram apresentados como uma forma de "participação da gerência", e as comissões de fábrica apareciam como o contraponto sindical da "ferramenta" gerencial. Já nos artigos do "trabalho participativo", as comissões de fábrica têm seu papel de opositor direto mitigado. Em alguns casos, elas apareciam como fontes de informações para que o sindicato pudesse negociar os processos de mudanças organizacionais, tornando-se uma espécie de "ferramenta sindical" e assim um instrumento despido de suas características libertárias de momentos anteriores. A pesquisa do DIEESE, "Trabalhadores e Inovações tecnológicas, Demandas e Perspectivas" de 1989, indicava na mesma direção dos artigos do Boletim DIEESE, ou seja, a "participação" estava relacionada à obtenção de informações sobre a introdução e implementação das mudanças organizacionais.

Assim, quando se compararam os significados atribuídos ao conceito de "participação" no transcorrer da década de oitenta, pode-se verificar uma diminuição na importância do papel das comissões na construção do conteúdo associado ao tema. No início da década, as Comissões de Fábrica surgiam como o principal significado associado ao tema, contando para isso com a divulgação alcançada pelas questões trabalhistas após 1978. Na metade da década, a disputa pelo significado atribuído ao tema participação encontra-se em uma situação de equilíbrio, tendo duas referências principais: As Comissões e Os Círculos de Controle de Qualidade. Já no final da década, é possível verificar um crescimento dos significados que associavam a participação características de uma ferramenta e atributo gerencial, com as comissões tendo um papel secundário na formulação do conceito atribuído ao tema.

Pode-se tecer duas hipóteses sobre o desfecho do processo no que tange ao papel dos sindicatos. De um lado, pode-se supor que, com a consolidação das centrais sindicais ocorrida no período, o essencial das energias dos militantes da área tenha sido canalizado para questões macro-estruturais ou institucionais. Como exemplo, a atuação da Central Única dos Trabalhadores no Programa Brasileiro de Qualidade e Produtividade, nos Fóruns institucionais de debates sobre as "Novas tecnologias" e no processo de elaboração da Constituição de 1988. 
Uma outra hipótese, não necessariamente antagônica, é a simples incapacidade do movimento sindical de manipular em seu proveito as novas tecnologias organizacionais. É possível constatar um indicativo de tal fato, numa entrevista concedida a este autor pelo diretor de Base dos Metalúrgicos do ABC paulista e uma das pessoas que vivenciaram o processo de implantação e desenvolvimento da Comissões de Fábrica da Volkswagem. Nela, o entrevistado reafirmava a posição de associar ao tema participação as Comissões de fábrica, lembrava das primeiras tentativas das Volkswagem de "trazer os trabalhadores para a empresa" com os "Programas de Sugestões", mas apontava os CCQs como o principal mecanismo que as empresas utilizaram para combater as comissões de fábrica. Entretanto, quanto à questão da introdução da "Administração Participativa" e outras formas mais recentes de "participação como ferramenta gerencial", ele admitia sua presença, mas não conseguia pesar as conseqüências da introdução dessas novidades para o trabalho de mobilização operária, a exemplo do que se passou na contraposição anterior entre os CCQs e as comissões de Fábrica.

\section{SíNTESE do PERÍOdo}

Assim, concluindo a cronologia do período, pode-se dizer que o conceito de participação percorreu um caminho muito interessante na sociedade industrial brasileira dos últimos vinte anos. Ele começou sua "carreira" como ponto fundamental das estratégias mais radicais do movimento operário que buscava a saída do circuito que envolvia o peleguismo sindical e autoritarismo governamental, para chegar ao limiar do século XXI como uma ferramenta gerencial quase perfeitamente pasteurizada. No final da década de setenta, o campo estruturado em torno da "participação" ainda não apresentava um pólo dominante claramente desenvolvido. Naquele momento, os membros das elites sindicais disputavam espaço (principalmente o espaço simbólico) com os gerentes que começavam a se apropriar do tema. No decorrer dos anos oitenta, a balança do poder no campo pendia cada vez mais para o lado gerencial. No final da década, mal podia ser percebido o papel dos sindicatos no tratamento do tema, indicando que no período ocorreu um fenômeno praticamente completo de apropriação dessa temática pelo universo gerencial.

Além disso, o outro importante resultado deste trabalho é ilustrar o fenômeno que Bourdieu chama de "alongamento dos circuitos de legitimação": os diversos grupos de atores, investidos ao mesmo tempo da condição de homens de ação e de intelectuais do novo tempo, não só concorrem entre si, mas também legitimam-se uns aos outros, através da recuperação parcial das construções de sentido já produzidas pelos seus contendores, procurando flexioná-las para nuanças que lhes seriam mais convenientes. Nua e cruamente, eles "estão no mesmo barco". O conceito divide a representação do patronato paulista exatamente no momento quente em que a velha elite da FIESP defronta-se com os "jovens turcos" no final da década de setenta (esta parece um questão em aberto, saber em que medida essa ruptura no seio do patronato abre espaço para que o conceito adquira legitimidade, em meios a ele subordinados funcional e ideologicamente); entre os gerentes, as diversas gerações, diversas funções e diversas origens disciplinares e sociais evidenciam suas diferenças por meio da apreciação de "se-ecomo deve-se permitir ou patrocinar a participação"; na academia, candidatos a diversos tipos de notoriedade digladiam-se, cada qual "conceituando" o tema de acordo com algum princípio que mistura aparência de rigor científico com uma plataforma para propaganda de consultoria, tentando mesclar justamente autoridade científica com dinamismo intervencionista. Mesmo entre as lideranças operárias, tencionadas pela questão do monopólio da representação de suas bases, aparecem conflitos táticos, estratégicos e semânticos, envolvendo o tema participação. A aparente independência e mesmo antagonismo entre os diversos grupos faz com que o conceito juntamente com os agentes que verbalizam ganhem todos muita legitimidade, segundo o princípio de que a máxima legitimidade é 
alcançada quando o consagrador esteja simbolicamente o mais distante possível do consagrado. Mais ainda, como o conceito acaba sendo construído e reconstruído incessantemente pelo trabalho cognitivo dessa afinidade de agentes e grupos, ele acaba virando uma "obra sem autor", dando-lhe o caráter de auto-evidente, ou pelo menos robustecendo a sua veracidade. Interessantemente, a pesquisa mostra que, participando da luta simbólica pela formatação do conceito, a elite sindical também participa do que Bourdieu denomina "campo do poder: o locus onde os possuidores das diversas formas de capital existentes na sociedade interagem, cada qual querendo fazer registrar como mais legítima a forma de que é detentor.

\section{Artigo recebido em 06.04.2001. Aprovado em 07.11.2001}

\section{BIBLIOGRAFIA}

BOURDIEU, P.: O Poder simbólico. Ed. Bertrand Brasil S.A: Rio de Janeiro, 1989.

COLE, R.: Strategies for Learning: Small Group Activities in American, Japanese and Swedish Industry, University of California Press, 1989.

DIEESE.: Trabalho e Reestruturação Produtiva: 10 anos de Linha de Produção. São Paulo.1994.

DONADONE, J.C.: Reestruturação produtiva e mudanças organizacionais: a difusão dos sistemas participativos na década de 1980, dissertação de mestrado, Departamento de engenharia de produção da Universidade Federal de São Carlos. Março de 1996.

HUCZYNSKI, A.:_Management Gurus.What makes them and how to become one Ed. Routledge. Chapman and Hall, Inc. New York, NY, 1993.

POWELL, W. W. \& DI MAGGIO, P. J.: "The iron cage revisited: institutional isomorphism and collective rationality in organizational fields". In: Powell, W. W., DIMAGGIO, P. J.: The new institutionalism in organizational analysis. p.63-82,University of Chicago Press, 1991.

REVISTA EXAME. Editora Abril. São Paulo. Nro 1 a 648. Ano: 1967 a 1990.

SEMLER, R. F.: Virando a própria mesa. Ed. Best Seller. São Paulo. 1988.

YOKOYAMA. N.: dissertação de mestrado em desenvolvimento no departamento de engenharia de produção da Universidade Federal de São Carlos sobre a difusão das técnicas japonesas no Brasil. julho de 1995. 